\title{
Opinions in science?
}

\section{Current Opinions in Solid State and \\ Materials Science}

Editors Anthony K. Cheetham, Hiroo

Inokuchi and John Meurig Thomas

Current Science. 6/yr. \$612.50, $£ 370.50$

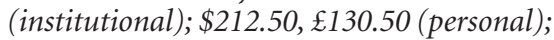

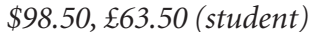

\section{Donald W. Murphy}

One of the principal challenges facing modern scientists is the assimilation and digestion of an enormous volume of literature from diverse sources. This is especially true in the important area of materials research, where major problems — such as energy storage and conversion, high-strength materials, and optical and electronic materials - are highly interdisciplinary, with academic tentacles in chemistry, physics and engineering. Keeping up to date with all the relevant literature is a tall order.

Current Opinion in Solid State and Materials Science endeavours to review selected areas within the scope of materials science on a regular basis.

The editors have divided materials science into 13 subject areas: electronic materials; solid catalysts and porous solids; optical and magnetic materials; synthesis and reactivity of solids; metals and alloys; biomaterials; amorphous materials; molecular crystals; characterization techniques; surface science; polymers; modelling and simulation of solids; and ceramics, composites and intergrowths.

Each issue of the journal addresses two or three of these subject areas in the form of a series of six to ten short reviews stressing the author's view of important trends, tied together by overviews written by the section editors.

The journal's title gives long-deserved recognition to the fact that opinions (especially about what is important) are a much more integral part of science than most scientists would like to admit. The journal encourages discussion along such lines, including the unique feature of marking ref-

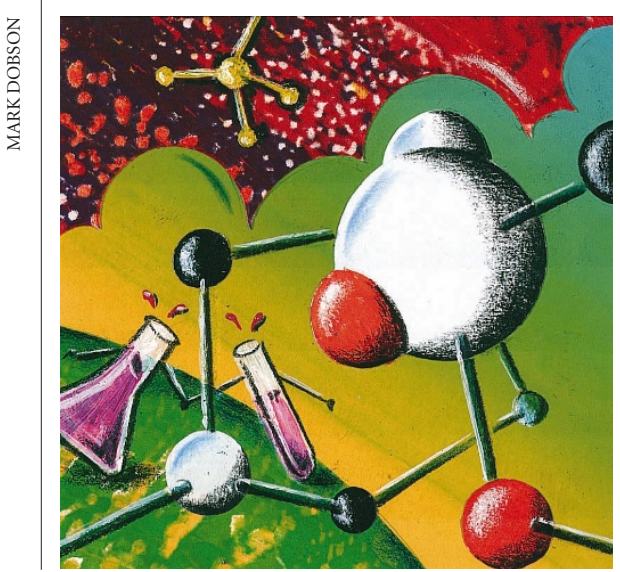

erences that are of special or outstanding interest.

The first issues have been of extremely high quality and of broad interest. I expect the articles will be of most use for either getting started on a new project or learning about areas outside one's field of expertise. There are not many journals that publish this type of article. The MRS Bulletin comes perhaps the closest, devoting about half of each issue to an ad hoc topic and the other half to news of the Materials Research Society.

A large obstacle to the success of this new Current Opinion journal is that it lacks the society base of the MRS Bulletin. This makes it more expensive (but not unreasonable in comparison with other unaffiliated journals) and not an automatic addition to personal or library collections. But if the quality of its first two years can be retained, materials scientists will surely want access to this journal.

Donald W. Murphy is at Lucent Technologies, Bell Laboratories, 700 Mountain Avenue, Murray Hill, New Jersey 07974, USA.

\section{Spice of life}

\section{JBIC: Journal of Biological Inorganic} Chemistry

Editor-in-chief Ivano Bertini

Springer. 6/yr. North America \$451, elsewhere DM660

\section{R.J.P.Williams}

Inorganic chemists are Johnny-comelatelies to biological chemistry. It is not their fault that this subject has been in the hands of organic chemists for many years. After all, organic chemistry began with a biological molecule, urea, nearly 200 years ago, while inorganic chemists pursued minerals rather than synthesizing materials.

Biological chemistry still appears in textbooks as if it were solely the domain of carbon chemicals decorated with nitrogen, hydrogen and oxygen as well as a good dash of sulphur and phosphorus atoms. And the pursuit of the catalysts of living organisms, which could have revealed the dominant value of inorganic elements long ago (not, of course, in colloidal form as thought by some workers early this century), appeared only to reinforce the triumphs of organic chemistry when the nickel enzyme urease was (mistakenly) analysed as having no metal ions. As late as 1955, Hans Krebs advised me not to waste my time studying metal ions in biological systems because all metal ions copurifying with proteins were likely to be impurities.

It is against this background that the Society of Biological Inorganic Chemistry and its new official publication, Journal of Biological Inorganic Chemistry, are to be welcomed. The editor-in-chief is clearly aware of the risks facing inorganic chemists attempting to break into the world of living organisms.

But in my view, the high wall separating inorganic chemistry from organisms was breached many years ago. Analysis in the past 50 years has shown that there is no life without some 15-20 elements and that most of these are inorganic. It is only ancient prejudice that sees organic carbon compounds, through their analytical dominance, as the essential ingredients of organisms. Inorganic elements can be likened to governors of society - few in number but powerful in effect. Think of iron compounds as catalysts, zinc compounds as transcription factors, calcium as the major second messenger, sodium and potassium as the essential current carriers in nerves - the list goes on and on. And can, for instance, connective tissue form without copper and zinc?

Many of these organismal roles are featured in the journal. Yet, on the basis of the first six issues, I fear that the inorganic chemists in the field are being far too introspective. Most of the articles are more about what inorganic chemists like to do than about biological chemistry. The pages abound with details on the stability and spectroscopic and magnetic properties of compounds, but these properties have no obvious consequences for the organisms from which the compounds have been extracted.

The inorganic chemist can, of course, learn something from these data, but will they help him or her to be part of the biological community? Will they establish inorganic chemical studies in biochemical textbooks? Such molecular studies have to be seen in relation to the examination of living organisms; otherwise the subject of the study is not biological inorganic chemistry but the inorganic properties of biological materials. I suspect that the future of biology will lie with systems analysis, not just with molecules. So what is the full functional value of an inorganic element in a compound in a system called a cell? Very few papers tackle such topics.

To be fair, there is much reason to hope that papers on real biological chemistry will increase. The field is already growing - not just in the ways I have mentioned but also in medicine and agriculture, and in the linkage between the inorganic chemical industry and the environment. The character of the atmosphere and that of the sea, and even that of clays, are very relevant and very inorganic.

There is a big future for this subject as well as for the journal and its society, but only if inorganic chemists bring out their lights from under the bushel and woo and wed the other biological sciences.

R. J. P. Williams is in the Inorganic Chemistry Laboratory, University of Oxford, South Parks Road, Oxford OX1 3QR, UK. 